EKATERINA V. PAVLOVA ${ }^{1 *}$

EVGENY A. IVANOV

VADIM E. KIRLUK ${ }^{2}$

VYACHESLAV V. ROZHNOV ${ }^{1}$

SERGEY V. NAIDENKO ${ }^{1}$
Studia Ecologiae et Bioethicae 13(2015)1, 107-122

\title{
Assessment of physiological status of felids as an indicator of their welfare in the wild
}

\begin{abstract}
Summary
One of the main approaches to monitoring the welfare of wild mammal populations in the wild is animal health estimation based on an analysis of their physiological parameters. To assess that for the natural felid populations, we analyzed adrenal activity level, white blood cells (WBC) counts and occurrence of seropositive reactions to different diseases. The first study was conducted in the Southwest Primorye, in natural habitats of Far Eastern leopard. Unevenly cold and snowy winters in 2010 and 2011 provided extreme natural conditions for overwintering mammals across the Russian Far East. Adrenocortical activity of leopards was significantly higher in 2011 (fecal cortisol level was $712.7 \pm 92.4 \mathrm{ng} \mathrm{g}^{-1}$ ) than in 2010 (361.4 $\left.\pm 80.5 \mathrm{ng} \mathrm{g}^{-1}\right)$. We suggest that abundance and availability of weakened deer and carcasses could facilitate hunting for leopards and help them to avoid starvation. In the second study we used WBC counts as a health index for three felid species: Pallas cat (Daursky State Nature Biosphere Reserve, 2010), Far Eastern leopard (Southwestern Prymorie, 2011), Siberian tiger (Ussuriskii Reserve, 2010-2011). The ratio of neutrophils to lymphocytes $(\mathrm{N}: \mathrm{L})$ was used as an indicator of stress and/or disease state. Occurrence of seropositive reactions to 12 different pathogens was analyzed in all the animals after the hematological analysis. Pallas cats had the lowest N:L

1 Russian Academy of Sciences, A.N. Severtsov Institute of Ecology and Evolution, Leninskij Prosp. 33, 119071 Moscow, Russian Federation, ${ }^{*}$ e-mail:pavlike@mail.ru.

2 Daursky State Nature Biosphere Reserve, Russian Federation.
\end{abstract}


ratio $(1.0 \pm 0.1)$, significantly differing from leopards $(42.8 \pm 16.0)$ and tigers $(24.5 \pm 9.2)$. The N:L ratio correlated with the occurrence of seropositive reactions but not with the pathogen diversity. Pallas cats had the lowest occurrence of positive reactions to 4 pathogens: Toxoplasma gondii (12.5\%), Mycoplasma sp. (12.5\%), influenza A (7.1\%), and feline leukemia virus (8.3\%). Leopards had the highest $\mathrm{N}: \mathrm{L}$ and occurrence of seropositive reactions only to 2 infections: T. gondii (16.6\%) and Candida sp. (100\%). On the contrary, tigers had positive responses to 6 pathogens, including canine distemper (7.7\%), feline immunodeficiency virus (8.3\%) and Aujeszky's disease (31\%), which were not found in other cats. Values of N:L depended also on the time spent to get blood samples. In the big felid species effects of glucocorticoids on the WBC ratio (neutrophilia) were obtained in blood samples from anesthetized animals, taken more than 2 hours after capture. In Pallas cats blood samples were collected within $13 \pm 2$ min without anesthesia. Thus the high N:L ratio in big felids can be explained by several reasons: stress of capture, immunosuppression and a high diversity of detected infections. The present findings may have important implications for creation of effective conservation strategies of rare felid species in the wild.

Key words: stress, hematology, serology, welfare, wild cats, Panthera pardus orientalis, Otocolobus manul, Panthera tigris altaica

\section{Introduction}

One of the approaches to assess welfare of animal populations in the wild is a monitoring of animal health based on physiological parameters. A hematological analysis allows to make preliminary conclusions on pathology occurrence. The pathological condition may be connected with stress and/or diseases (infections, parasites etc.). Animal disturbance may adversely affect their reproduction, survival, welfare and finally - the persistence of wild populations (Brown et. al. 1994, Roelke-Parker et al. 1996, Sapolsky et. al. 2000, Wingfield and Romero 2001, Meli et al. 2009). The assessment of animal health serves as a good indicator of their welfare and is an essential parameter for the development of conservation strategy of rare species. 
An investigation of the physiological status of animals in the wild is associated with some problems. Two of them are the most important: (1) a selection of the most suitable method to assess physiological parameters needed, (2) a definition of reference scales for different physiological parameters and species, to determine healthy/unhealthy state of animals studied.

Traditionally there are two approaches to estimate physiological parameters: invasive and non-invasive methods. Invasive methods suggest a capture of animals and collecting their blood samples. These methods give preliminary conclusions about animals' state on the basis of hematological analysis: they register the stress level of an animal (by measuring glucocorticoid concentration in blood plasma as an index of its adrenal activity) and estimate occurrence of seropositive reactions to different diseases by measuring concentration of specific IgG.

However, the process of animal immobilization is not only extremely effortful, but also stressful for wild animals and may affect physiological parameters (glucocorticoid levels, leukocyte profiles etc.) (Meyer and Harvey 2007). That is why non-invasive methods for monitoring of physiological status, especially of hormonal activity, became more preferable (Miller et al. 1991, Gerlinskaya et al. 1993, Mostl and Palme 2002). These methods are based on measurement of concentration of steroids and steroid metabolites in various excreta (feces, urine, etc.) and can be carried out without any direct contact with animals (Hay and Mormede 1998, Mostl and Palme 2002). Therefore, non-invasive methods do not affect physiological indices of hormonal activity. However, non-invasive methods must be validated before their application for every animal species (Touma and Palme 2005).

Each animal species has its own reference values for every physiological parameter (e.g. leukocyte profile), when an animal may be considered healthy. The reference interval depends on many factors: species, sex, age, season, individual differences, stage of reproductive cycle etc. (Lumsden 1998, Touma and Palme 2005). These factors should be taken into account when estimating animal welfare, otherwise there 
is a risk to take the norm as pathology and vice versa. Unfortunately, for the majority of mammalian species, especially rare ones, there is no information about the basal values of physiological parameters.

In the present study we considered the applicability of physiological indexes (adrenocortical activity assessed noninvasively by fecal glucocorticoids concentration, leukocyte profiles and occurrence of seropositive reactions to different diseases) for welfare assessment of three rare species of wild cats: Far Eastern leopard (Panthera pardus orientalis), Pallas cat (Otocolobus manul), Siberian tiger (Panthera tigris altaica). We focused on: 1) the use of a fecal cortisol level to estimate an influence of natural factors (weather conditions and food availability) on adrenal activity of leopards, 2) the estimation of the health status using reference blood values and occurrence of seropositive reactions to feline pathogens, 3) the comparison of the data of hematological and serological analyses. The present study is the first one, where a complex comparative investigation of health status as the assessment of welfare for three rare felid species was done.

\section{Materials and methods}

\subsection{Analysis of adrenal activity}

The study was conducted in the natural habitat of Far Eastern leopard, in the forested mountains of the East Manchurian Mountain Range (Southwestern Primorye). An unevenly cold and snowy winters of 2010 and 2011 provided extreme conditions for the wild mammals in the Russian Far East. Thus, a deep snow cover hampered movements and complicated foraging for ungulates. A great number of sika deer Cervus nippon were weakened and died of starvation (Maslov 2012). To estimate the influence of the winter conditions on leopards we compared their adrenal activity during two periods with different weather, using noninvasive estimation of cortisol metabolites from farces. Fecal samples were collected in the course of routes during annual tiger and leopard surveys in the Russian Far East (WCS 2010) in February $2010(\mathrm{n}=11)$ and $2011(\mathrm{n}=28)$. After extraction with $90 \%$ methanol (Jewgenow et al. 2006), samples were assayed for cortisol 
metabolites with commercial enzyme immunoassay (EIA) kit for cortisol (Immunotech, Moscow, Russia). The concentrations were assessed with Multiscan EX Microplate Photometer (ThermoElectron Corporation). This method for noninvasive assessment of adrenocortical activity was validated for Far Eastern leopard with transportation test and ACTH-challenge test (Ivanov 2011). To describe weather conditions, we analyzed data from Barabash weather station located about $30 \mathrm{~km}$ southward from the survey area.

\subsection{Hematological analysis}

We estimated percentages of the different leucocyte types (neutrophils, lymphocytes, eosinophils, monocytes and basophils) in the blood smears of three felid species: Pallas cat (16 animals, Daursky State Nature Biosphere Reserve, 600-800 m a.s.l., spring 2010), Far Eastern leopard (6 animals, Southwestern Prymorie, summer - autumn 2011), Siberian tiger (13 animals, Ussuriskii reserve, summer - autumn 2011). The relative proportion of neutrophils to lymphocytes (N:L) is often considered as a composite measure of stress response, since numbers of neutrophils and lymphocytes are affected by stress in opposite directions. This ratio is positively related to the magnitude of a stressor and to the level of circulating glucocorticoids. There is also evidence that this ratio is influenced by diseases and infections (stress hormones' production is also caused by infections) (Davis et al. 2008). Therefore, $\mathrm{N}: \mathrm{L}$ ratio was used in this study as an indicator of pathological conditions (stress and/or disease).

Capturing is stressful for animals, which may be reflected in blood parameters. We used different methods of capture for small and big cats. The main difference was the time spent to get the blood samples. Aldridge snares and immobilization with anesthesia (the mix: Dormitor, Orion Corporation, Finland, $20 \mu \mathrm{g} \mathrm{kg}^{-1}+$ Zoletil, Virbak, France, $2,5 \mathrm{mg} \mathrm{kg}^{-1}$ of the animal body weight) were used for tigers and leopards. Blood samples were taken in more than $2 \mathrm{~h}$ after the animal capture (Rozhnov et al. 2011). Blood samples from Pallas cats were taken within $13 \pm 2$ min after the manual capture, without anesthesia. All the blood samples (volume 1- $20 \mathrm{ml}$ ), were collected 
from femur vein. About $0.25 \mathrm{ml}$ of sample blood was placed into a small tube with EDTA and kept in a cool place before making a smear. Blood smears were made $2-4 \mathrm{~h}$ after the blood collecting. White blood cell (WBC) counts in the smears were made using the microscope (Leica Microsystems, Switzerland, magnification 10/25100) at the Biological Science Station „Thernogolovka” of A. N. Severtsov Institute of Ecology and Evolution RAS near Moscow.

\subsection{Serological analysis}

Results of blood analysis were supported by serological analysis in all studied animals. We analyzed occurrence of seropositive reactions to 12 different pathogens in all animals where hematological analysis had been done (see Table 2). Methods of serological analysis were described by Naidenko et al. (2012). All the analyses were conducted at the Biological Science Station „Thernogolovka” of A. N. Severtsov Institute of Ecology and Evolution RAS.

\subsection{Statistical analysis}

Statistical analysis was performed using Statistica 8.0. Nonparametric tests were used for the data that did not fit the normal distribution (Kolmogorov-Smirnov test) and for the samples with little number of animals. Mann-Whitney test was used to access differences in leopard adrenal activity levels between 2010 and 2011, and also to analyze differences in WBC ratio in three felid species. Results with error probability values $P<0.05$ were considered significant.

\section{Results}

\subsection{Analysis of adrenal activity}

Adrenocortical activity of leopards was significantly higher in February 2011 than 2010 (Mann-Whitney test: $\mathrm{N}_{1}=11, \mathrm{~N}_{2}=28, \mathrm{Z}=$ $2.09, P<0.05)$. Fecal cortisol concentration in 2011 reached $712.7 \pm$ $92.4 \mathrm{ng} \mathrm{g}^{-1}$, while in 2010 it was $361.4 \pm 80.5 \mathrm{ng} \mathrm{g}^{-1}$ (Fig. 1). 


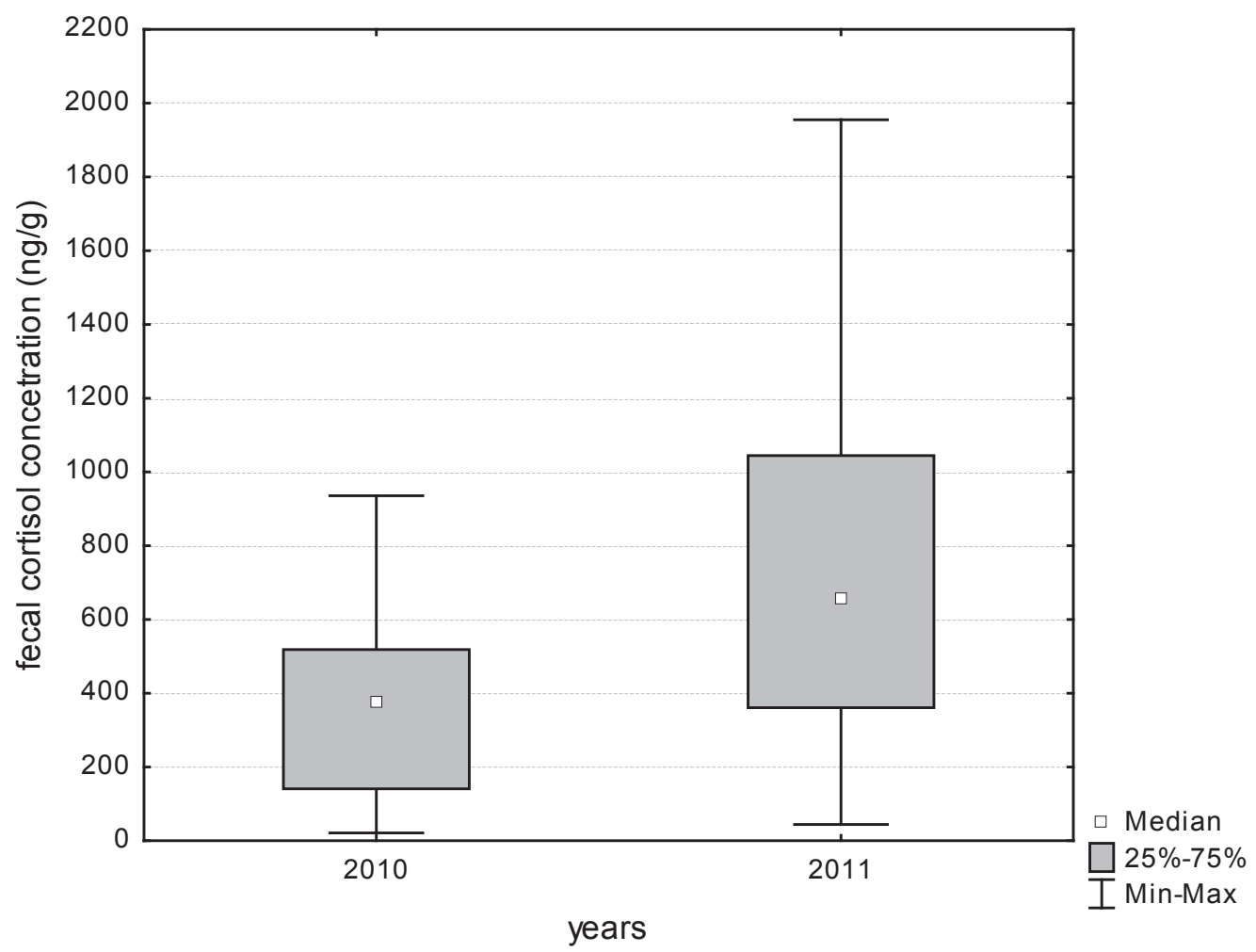

Fig. 1. Fecal cortisol concentration in February $2010\left(\mathrm{~N}_{1}=11\right)$ and February $2011\left(\mathrm{~N}_{2}\right.$ = 28) for Far Eastern leopards. Differences statistically significant (Mann-Whitney test, $P<0.05)$.

\subsection{Hematological analysis}

No significant differences were observed in WBC proportions between three cat species, with the following exceptions: Pallas cats had a higher percentage of lymphocyte and lower percentage of neutrophils than tigers and leopards. In tigers and leopards, the N:L ratio was significantly shifted to the prevalence of neutrophils. The leopards had the highest percent of neutrophils and the lowest percent of lymphocytes. Consequently, N:L ratio was the highest in leopards, being significantly different from the one in Pallas cats $\left(\mathrm{N}_{1}=6, \mathrm{~N}_{2}=\right.$ $16, \mathrm{Z}=3.5, P<0.0001$ ) (Table 1).

Tab. 1. Average $(\mathrm{M} \pm \mathrm{SE})$ white blood cell $(\mathrm{WBC})$ values for three species of wild cats. $\mathrm{WBC}$ types: $\mathrm{Lym}=$ lymphocytes, Mon $=$ monocytes, Eos $=$ eosinophils, Bas =basophils, $\mathrm{Neu}=$ neutrophils, $\mathrm{N}: \mathrm{L}=$ ratio between neutrophils and lymphocytes. 
$\mathrm{N}$ - number of tested animals. Symbol * indicates significant differences (MannWhitney U Test, $P<0.001)$. Significant differences were found between such parameters as Lym, Neu and N:L in Otocolobus manul and Lym, Neu and N:L in Panthera pardus and Panthera tigris, respectively.

\begin{tabular}{lcccccc}
\hline Spiecies & Lym (\%) & Mon (\%) & Eos (\%) & Bas (\%) & Neu (\%) & N:L \\
\hline $\begin{array}{l}\text { Panthera par- } \\
\text { dus }(\mathrm{N}=6)\end{array}$ & $4.2 \pm 1.5^{*}$ & $6.8 \pm 1.5$ & $0.8 \pm 0.0$ & $0.0 \pm 0.0$ & $88.4 \pm 2.0^{*}$ & $42.8 \pm 16.0^{*}$ \\
$\begin{array}{l}\text { Panthera } \\
\text { tigris }(\mathrm{N}=13)\end{array}$ & $14.7 \pm 5.7^{*}$ & $8.2 \pm 2.4$ & $1.3 \pm 0.6$ & $0.3 \pm 0.1$ & $75.4 \pm 7.3^{*}$ & $24.5 \pm 9.2^{*}$ \\
$\begin{array}{l}\text { Otocolobus } \\
\text { manul }(\mathrm{N}=16)\end{array}$ & $46.9 \pm 3.7^{*}$ & $12 \pm 1.9$ & $1.2 \pm 0.3$ & $0.5 \pm 0.4$ & $39.0 \pm 4.0^{*}$ & $1.0 \pm 0.1$ \\
\hline
\end{tabular}

\subsection{Serological analysis}

Serological analysis has shown that that tigers and leopards had $100 \%$ of positive reactions to diseases (each animal had a positive reaction to at least one disease). In contrast, the majority of Pallas cats had negative reactions to many feline pathogens. For the rest of pathogens, the occurrence of positive reactions did not exceed $12.5 \%$ of animals (Table 2). The lowest diversity of diseases in positive serological test was found for leopards. We found positive results for only two infections: Toxoplasma gondii (16.6\%) and Candida sp. (100\%). On the contrary, in tigers positive results were found to six pathogens, including canine distemper (7.7\%), feline immunodeficiency virus (FIV) (8.3\%) and Aujeszky's disease (31\%), which were not found in other cats.

To compare the welfare of the species studied, we combined results of hematological and serological analyses. It was found that $\mathrm{N}: \mathrm{L}$ ratio correlated with the occurrence of seropositive reactions but not with pathogen diversity (Fig. 2.). Pallas cats had the lowest N:L ratio and the lowest percent of occurrence of positive reactions to the pathogens detected. Tigers had the greatest diversity of positive reactions. Their $\mathrm{N}$ :L ratio was high, but smaller than that of leopards. 


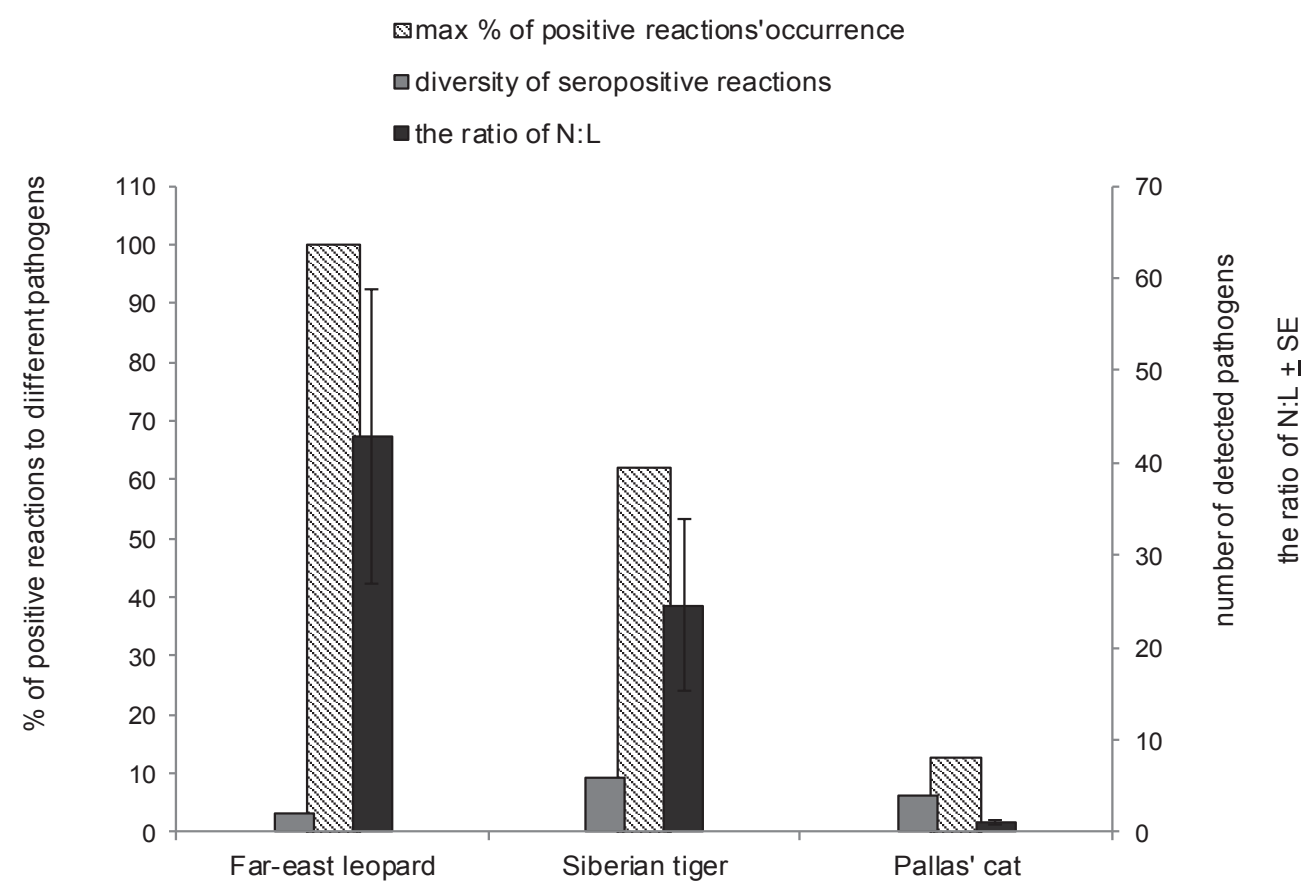

Fig. 2. Ratio of N:L, max percent of seropositive reactions and diversity of seropositive reactions to different pathogens in three species of wild cats.

\section{Discussion}

4.1. Activity of adrenal system as an indicator of animal stress and a parameter of welfare

Traditionally fluctuations of weather conditions are considered as an unpredictable factor of the environment, together with fluctuations of food availability, sudden changes in social status, increased predator pressure, diseases and perturbations in local habitat or social status (Wingfield et al. 1998; Wingfield and Ramenofsky 1999, Wingfield and Romero 2001). Unpredictable events may cause changes in energetic demands of animals, provoke an increase of adrenal activity level and consequently elevate glucocorticoid level. Inhibition of the reproductive system, suppression of the immune system, promotion of severe protein loss (muscle wasting), disruption of second cell messengers, neuronal cell malfunction and suppression of growth are chronic effects (lasted days to weeks) of continued high circulating levels of glucocorticoids in response to direct perturbation factors (Sapolsky et al. 2000, Wingfield and Romero 2001). But 
glucocorticoids do not merely act as „stress hormones”. They carry out a number of important roles in metabolism at both basal and stress-induced levels. It has been shown that increase of locomotory activity positively correlates with the level of adrenal activity. It is responsible for mobilization of needed energy by promoting gluconeogenesis, especially from protein (Chester-Jones et al. 1972).

Our results show that during a severe winter (with the average temperature of $-12^{\circ} \mathrm{C}$ and snow cover depth of $30.9 \mathrm{~cm}$ in February 2010), adrenal activity of leopards was significantly lower than during normal winter (with the average temperature of $-8.7^{\circ} \mathrm{C}$ and snow cover depth of $20.4 \mathrm{~cm}$ in February 2011). We suppose that in this case food availability played the key role in leopard adrenal activity. Abundance and availability of weakened deer and their carcasses could facilitate hunting for leopards and help them to avoid starvation. The increased food intake could help leopards to overcome the adverse weather conditions.

\subsection{Hematological and serological analyses as indicators of animals' health and parameters of welfare}

The N:L ratio was the lowest in Pallas cats as compared with the big cats. Meyer and Harvey (2007) found a similar value of the N:L ratio (1.75) in healthy domestic cats (Felis catus). In relation to the reference value of domestic cats (the mean content of lymphocytes equal to 33\% (Meyer and Harvey 2007)), Pallas cats had the higher percent of lymphocytes in blood (47\%), which can be called lymphocytosis. Most probably, lymphocytosis is caused by the release of adrenaline in response to a brief increase of lymph flow during the muscle activity (Cowell and Decker 2000). In our study, during the capture of Pallas cats, the animals moved actively. Furthermore, during the manual immobilization and collecting of blood samples, an increased stress level can also be expected. In contrast, in tigers and leopards a very high percentage of neutrophils was observed: $75 \%$ and $88 \%$, respectively (we can call it neutrophilia) in relation to their content in health domestic cat (58\%) (Meyer and Harvey 2007). On the other hand, a free-ranging Iberian lynx had also a high 
percentage of neutrophils (85\%) (blood samples were collected from anesthetized animals) (Beltran et al. 1991). In this case, neutrophilia could be caused by secretion of glucocorticoids, which significantly affects the number of WBC by increasing secretion of neutrophils from marrow into the blood stream (Meyer and Harvey 2007, Davis et al. 2008).

Glucocorticoid secretion increases within minutes in response to stressful situations (Sapolsky et al. 2000), in our case due to a prolonged (more than for two hours) immobilization of anesthetized animals. Thus the reason why the effect of glucocorticoids on the WBC ratio was not caught by us in the case of Pallas cats could be the fact that secretion of steroid hormones occurred later, after obtaining blood samples from animals.

Tab. 2. Occurrence of seropositive reaction to different feline pathogens in three species of wild cats. FIV - feline immunodeficiency virus, FeLV - feline leukemia virus, FCoV - feline coronavirus. For all pathogens percent of positive reactions and the number of tested animals $(\mathrm{N})$ are presented.

\begin{tabular}{lccc}
\hline Pathogen & Panthera pardus & Panthera tigris & Otocolobus manul \\
\hline Herpes & $0(\mathrm{~N}=6)$ & $0(\mathrm{~N}=13)$ & $0(\mathrm{~N}=16)$ \\
Toxoplasma gondii & $16.6(\mathrm{~N}=6)$ & $46.2(\mathrm{~N}=13)$ & $12.5(\mathrm{~N}=16)$ \\
Parvovirus & $0(\mathrm{~N}=6)$ & $0(\mathrm{~N}=12)$ & $0(\mathrm{~N}=16)$ \\
Canine distemper & $0(\mathrm{~N}=6)$ & $7.7(\mathrm{~N}=13)$ & $0(\mathrm{~N}=16)$ \\
Chlamidia sp. & $0(\mathrm{~N}=6)$ & $0(\mathrm{~N}=13)$ & $0(\mathrm{~N}=16)$ \\
Mycoplasma sp. & $0(\mathrm{~N}=6)$ & $7.7(\mathrm{~N}=13)$ & $12.5(\mathrm{~N}=16)$ \\
FIV & $0(\mathrm{~N}=6)$ & $8.3(\mathrm{~N}=12)$ & $0(\mathrm{~N}=10)$ \\
FeLV & $0(\mathrm{~N}=6)$ & $0(\mathrm{~N}=12)$ & $8.3(\mathrm{~N}=16)$ \\
FCoLV & $0(\mathrm{~N}=6)$ & $0(\mathrm{~N}=12)$ & $0(\mathrm{~N}=13)$ \\
Influenza A & $0(\mathrm{~N}=6)$ & $0(\mathrm{~N}=12)$ & $7.1(\mathrm{~N}=14)$ \\
Aujeszky's Disease & $0(\mathrm{~N}=6)$ & $31(\mathrm{~N}=13)$ & $0(\mathrm{~N}=11)$ \\
Candida sp. & $100(\mathrm{~N}=6)$ & $61.5(\mathrm{~N}=13)$ & $0(\mathrm{~N}=14)$ \\
\hline
\end{tabular}


However, neutrophilia could be caused not only by stress but also by inflammatory processes (bacterial and viral infections, fungous and protozoan diseases) and bleeding as well (Lucroy and Madewall 2001, Witko-Sarsat et al. 2000). Therefore the high ratio of N:L observed in this study could be caused by any disease in tigers and leopards. The ratio of N:L was correlated with the percent of positive reactions to some pathogens among cats, but not with the diversity of infections. It is possible that a high $\mathrm{N}: \mathrm{L}$ ratio in leopards $(>60)$ was the result of both the stress from capture and the fungal disease (caused by Candida sp. discovered in all the animals tested). In tigers this effect was weaker since the maximal percent of positive tests to any disease was not higher than $65 \%$. These results differed significantly from Pallas cats which had the lowest percent of positive tests to any disease (only 12.5\%) and the low diversity of diseases.

Thus, a comparison of the welfare among the three cat species on the basis of a combination of hematological and serological analyses, suggests that Pallas cats in the study area were in the best condition. In contrast, leopards and tigers showed a more stressful condition. Leopards had the highest ratio of N:L. There can be two reasons of such situation: stress of capture and immunosuppression. The second reason may be confirmed by $100 \%$ of positive results to Candida sp. This fungi often develops as concurrent infection because of immunosuppression caused by other disease, for example Toxoplasma gondii (see Table 2), or other factors. Tigers also had the high ratio of $\mathrm{N}: \mathrm{L}$ and this fact could be caused by both stress of capture and high diversity of detected infections including the most dangerous for cats, such as canine distemper, FIV and Aujeszky's disease (Hoover et al. 1975, Hardy et al. 1976, Torten et al. 1991, Meli et al. 2009).

\section{Conclusion}

The monitoring of welfare by means of assessment of physiological status offers several advantages and can be applied to various species of wild felids. Our findings provide opportunity to use fecal cortisol metabolites to assess complex effects of environmental stressors 
(e.g. of weather changes and prey availability) on adrenal activity of animals in the wild. Results of hematological and serological analyses allow estimations of the complex effects of various factors (a reaction of immune system to pathogens, infection-caused stress and procedure-induced negative effects) and may be used as indicators of welfare. However, since stressful procedures (such as capturing and immobilizing of animals) may affect the ratio of WBC, we suggest that the comprehensive information about methods of animal capture should be taken into account when interpreting the results of such studies. Our results may be important to create effective conservation strategies of three rare species of felids in the wild.

\section{Acknowledgements}

We would like to thank all colleagues from Daursky State Nature Biosphere Reserve and Ussuriskii Reserve for technical assistance in taking blood and fecal samples. We also would like to thank Anastasia Antonevich for the help with English text. This work was supported by the Russian Foundation for Basic Research, Project no.12_04_32028 and the III.10 grant of the Biological Resources program, General Biology Department, Russian Academy of Sciences. This paper was presented during the V Russian-Polish School of Young Ecologists organized by Center for Ecological Research Polish Academy of Sciences, which took place in Gdańsk in September 2012.

\section{References}

Beltran J.F., Delibes M., Recio F., Aza C., 1991, Hematological and serum chemical characteristics of the Iberian Lynx (Lynx pardinus) in South-western Spain, Canadian Journal of Zoology 69, 840-846.

Brown E.W., Yuhki N., Packer C., O’Brien S.J., 1994, A lion lentivirus related to feline immunodeficiency virus: epidemiologic and phylogenetic aspects, Journal of Virology 68, 5953-5968.

Chester-Jones I., Bellamy D., Chan D. K. O., Follett B. K., Henderson I. W., Phillips J. G., Snart R. S., 1972, Biological actions of steroid 
hormones in non-mammalian vertebrates, in: Idler A.Z. (ed.), Steroid in non-mammalian vertebrates, Academic Press, New York, 414-480. Cowell R.L., Decker L.S., 2000, Interpretation of feline leukocyte responses, in: Feldman B.F., Zinkl J. G., Jain N.C., Schalm's veterinary hematology, $5^{\text {th }}$ ed., Lippincott, Williams and Wilkins, Philadelphia, 382-390.

Davis A.K., Maney D.L., Maerz J.C., 2008, The leukocyte profiles to measure stress in vertebrates: a review for ecologists, Functional Ecology 22, 760-772.

Gerlinskaya L.A., Moshkin M.P., Evsikov V.I., 1993, The methodical approaches to estimation of stress in wild mammals, Ecology, 1, 97-99 (in Russian).

Hardy W.D.Jr., Hess P.W., MacEwen E.G., McClelland A.J., Zuckerman E.E., 1976, Biology of feline leukemia virus in the natural environment, Cancer Research 36, 582-588.

Hay M., Mormede P., 1998, Urinary excretion of catecholamines, cortisol and their metabolites in Meishan and Large White sows: validation as a non-invasive integrative assessment of adrenocortical and symphatoadrenal axis activity, Vet Res. 29, 143-158.

Hoover E.A., Olsen R.G., Hardy W.D.Jr., Schaller J.P., Mathes L.E., Cockerell G.L., 1975, Biologic and immunologic response of cats to experimental infection with feline leukemia virus, Bibliotheca Haematology 180-183.

Ivanov E.A., 2011, Validation and using of non-invasive method of monitoring of cortisol in Far Eastern leopard (Panthera pardus orientalis), in: V. V. Rozhnov (ed.), Current problems of ecology and evolution in the studies of young scientists. Proceedings of the Conference of PhD student and young scientists of A. N. Severtsov Institute of Ecology and Evolution of Russian Academy of Science, KMK, Moscow, 21 (in Russian).

Jewgenow K., Naidenko S.V., Goeritz F., Vargas A., Dehnhard M., 2006, Monitoring testicular activity of male Eurasian (Lynx lynx) and Iberian (Lynx pardinus) lynx by fecal testosterone metabolite measurement, Gen. Comp. Endocrin. 149, 2, 151-158. 
Lucroy M.D., Madewall B.R., 2001, Clinical outcome and diseases associated with extreme neutrophilic leukocytosis in cats: 104 cases, J. Am. Vet. Med. Assoc. 218, 736-739.

Lumsden J.H., 1998, „Normal” or reference values: Questions and comments, Vet. Clin. Pathol. 27, 102-106.

Maslov M.V., 2012, Habitations' characteristics of sika deer (Cervus nippon) in Ussuriskii reserve, Biology Soil Institute, Vladivostok, 24 (in Russian).

Meli M.L., Cattori V., Martínez F., López G., Vargas A., 2009, Threats to the Iberian lynx (Lynx pardinus) by feline pathogens. Iberian lynx ex-situ conservation: an interdisciplinary approach, Fundación Biodiversidad, Madrid, Spain, 220-233.

Meyer D.J., Harvey J.W., 2004, Veterinary laboratory medicine. Interpretation and diagnosis, Elsevier Inc., New York.

Miller M.W., Hobbs N.T., Sousa M.C., 1991, Detecting stress responses in rocky mountain bighorn sheep (Ovis canadensis canadensis): reability of cortisol concentrations in urine and feces, Can. J. Zool. 69, 15-24.

Mostl E., Palme R., 2002, Hormones as indicators of stress, Domestic animals endocrinology 23, 67-74.

Naidenko S.V., Esaulova N.V., Lukarevskii V.S., Hernandez-Blanko J.A., Sorokin P.A., Litvinov M.N., Kotlyar A.K., Rozhnov V.V., 2012, Occurence of infection diseases in Amur tigers in the south of their range, in: Seryodkin I.V., Miquelle D.G. (eds), Deases and parasites of wildlife in Siberia and the Russian Far East, Dalnauka, Vladivostok.

Roelke-Parker M.E., Munson L., Packer C., Kock R., Cleaveland S., 1996, A canine distemper virus epidemic in Serengeti lions, Nature 379, 441-445.

Rozhnov V.V., Hernandez-Blanko J.A., Lukarevskii V.S., Naidenko S.V., Sorokin P.A., Litvinov M.N., Kotlyar A.K., Pavlov D.S., 2011, An application of satellite collars to study home range and activity of the amur tiger (Panthera tigris altaica), Zool. J. 90, 580-594.

Sapolsky R.M., Romero L.M, Munck A.U., 2000, How do glucocorticosteroids influence stress responses? Integrating permissive, suppressive, stimulatory, and preparative actions, Endocrine Reviews 21, 55-89. 
Torten M., Franchini M., Barlough J.E., George J.W., Mozes E., 1991, Progressive immune dysfunction in cats experimentally infected with feline immunodeficiency virus, Journal of Virology 65, 2225-2230.

Touma C., Palme R., 2005, Measuring fecal glucocorticoid. Metabolites in mammals and birds: The importance of validation, Ann. N. Y. Acad. Sci., 1046, 54-74.

Wingfield J.C., Breuner C., Jacobs J., Lynn S., Maney D., Ramenofsky M., Richardson R., 1998, Ecological bases of hormone-behavior interactions: the „emergency life history stage”, Amer. Zool., 38, 191-206.

Wingfield J. C., Ramenofsky M., 1999, Hormones and the behavioral ecology of stress, in: B. W. Balm (ed.), Stress physiology in animals, Sheffield Academic Press, Sheffield, 1-51.

Wingfield J. C., Romero L. M., 2001, Adrenocortical responses to stress and their modulation in free-living vertebrates, in: McEwen C.V. (ed.), Handbook of physiology, Oxford University Press, Oxford, 211-236.

Witko-Sarsat V., Rieu P., Descamps-Latscha B., 2000, Neutrophils: molecules, functions, and pathophysiological aspects, Lab. Invest. $80,617-653$. 